\title{
TU/e EmonOWEN

\section{Continuous-flow multistep synthesis of cinnarizine, cyclizine, and a buclizine derivative from bulk alcohols}

\section{Citation for published version (APA):}

Borukhova, S., Noël, T., \& Hessel, V. (2015). Continuous-flow multistep synthesis of cinnarizine, cyclizine, and a buclizine derivative from bulk alcohols. ChemSusChem, 9(1), 67-74. https://doi.org/10.1002/cssc.201501367

DOI:

10.1002/cssc. 201501367

Document status and date:

Published: 09/12/2015

\section{Document Version:}

Publisher's PDF, also known as Version of Record (includes final page, issue and volume numbers)

\section{Please check the document version of this publication:}

- A submitted manuscript is the version of the article upon submission and before peer-review. There can be important differences between the submitted version and the official published version of record. People interested in the research are advised to contact the author for the final version of the publication, or visit the $\mathrm{DOI}$ to the publisher's website.

- The final author version and the galley proof are versions of the publication after peer review.

- The final published version features the final layout of the paper including the volume, issue and page numbers.

Link to publication

\section{General rights}

Copyright and moral rights for the publications made accessible in the public portal are retained by the authors and/or other copyright owners and it is a condition of accessing publications that users recognise and abide by the legal requirements associated with these rights.

- Users may download and print one copy of any publication from the public portal for the purpose of private study or research.

- You may not further distribute the material or use it for any profit-making activity or commercial gain

- You may freely distribute the URL identifying the publication in the public portal.

If the publication is distributed under the terms of Article 25fa of the Dutch Copyright Act, indicated by the "Taverne" license above, please follow below link for the End User Agreement:

www.tue.nl/taverne

Take down policy

If you believe that this document breaches copyright please contact us at:

openaccess@tue.nl

providing details and we will investigate your claim. 


\title{
Continuous-Flow Multistep Synthesis of Cinnarizine, Cyclizine, and a Buclizine Derivative from Bulk Alcohols
}

\author{
Svetlana Borukhova, ${ }^{[a]}$ Timothy Noël, ${ }^{*[a, b]}$ and Volker Hessel ${ }^{*[a]}$
}

Cinnarizine, cyclizine, buclizine, and meclizine belong to a family of antihistamines that resemble each other in terms of a 1-diphenylmethylpiperazine moiety. We present the development of a four-step continuous process to generate the final antihistamines from bulk alcohols as the starting compounds. $\mathrm{HCl}$ is used to synthesize the intermediate chlorides in a short reaction time and excellent yields. This methodology offers an excellent way to synthesize intermediates to be used in drug synthesis. Inline separation allows the collection of pure products and their immediate consumption in the following steps. Overall isolated yields for cinnarizine, cyclizine, and a buclizine derivative are 82,94 , and $87 \%$, respectively. The total residence time for the four steps is $90 \mathrm{~min}$ with a productivity of $2 \mathrm{mmolh}^{-1}$.

\section{Introduction}

Functional group interconversion is one of the most used techniques in drug synthesis. ${ }^{[1]}$ The conversion of hydroxyl groups to their corresponding halides is arguably one of the most versatile transformations, which is often followed by a nucleophilic substitution. Therefore, this is one of the key research areas in the synthesis of active pharmaceutical ingredients (APIs). ${ }^{[2]}$ Chlorides are very interesting because of their abundance in nature and their low molecular weight. The synthesis of chloride derivatives from alcohols usually requires the use of chlorinating agents such as thionyl chloride, ${ }^{[3]}$ phosphorus chlorides $_{,}{ }^{[4]}$ pivaloyl chloride, ${ }^{[5]}$ Vilsmeier reagent, ${ }^{[6]}$ tosyl chloride, ${ }^{[7]}$ 2,4,6-trichloro-[1,3,5]triazine with $\mathrm{DMF}^{[8]}$ oxalyl chloride, ${ }^{[9]}$ and phosgene. ${ }^{[10]}$ Unfortunately, these chlorinating agents have high toxicities. ${ }^{[11]}$ Moreover, as only a part of the chlorinating agent molecule is used in the reaction, waste is generated in stoichiometric amounts, which leads to a process that is not atom efficient or green. ${ }^{[12]}$

The ideal process to convert primary alcohols to the corresponding chlorides is based on the reaction of neat alcohol with hydrogen chloride. This will maximize atom efficiency and result in water as the sole by product. Although possible, the handling of hydrogen chloride gas is challenging, especially on a large scale. Hydrochloric acid can be used as an alternative. However, low to average temperatures need to be maintained to keep the solubility of hydrogen chloride in water sufficiently

[a] S. Borukhova, Dr. T. Noël, Prof. Dr. V. Hessel

Department of Chemical Engineering and Chemistry

Technische Universiteit Eindhoven

Den Dolech 2, 5600 MB Eindhoven (Netherlands)

E-mail:t.noel@tue.nl v.hessel@tue.nl

[b] Dr. T. Noël

Department of Organic Chemistry

Ghent University

Krijgslaan 281 (S4), 9000 Ghent (Belgium)

$\square$ Supporting Information for this article is available on the WWW under http://dx.doi.org/10.1002/cssc.201501367. high. ${ }^{[13]}$ Thus, reaction rates can only be increased to a limited extent in batch reactors. In contrast to batch reactors, microflow technology offers an excellent platform to enable this sort of processes. ${ }^{[14-17]}$ The absence of headspace and safe pressurization within microchannels helps to keep hydrogen chloride dissolved at high reaction temperatures. Multiple examples of reaction rate acceleration in microreactors under high temperature and pressure exist. ${ }^{[18-21]}$ In addition, the modularity of continuous-flow reactors allows the construction of reaction networks to deliver natural products ${ }^{[22,23]}$ and $\mathrm{APIs}^{[24-29]}$ in a safe, quick, and efficient way.

Several milestones have been reached in the conversion of alcohols to chlorides, that is, chlorodehydroxylation. Tundo et al. have described a solvent-free synthetic method, that is, gas-liquid phase-transfer catalysis (GL-PTC), in which a gaseous reagents flow through a molten phase-transfer catalyst supported on a solid. ${ }^{[30,31]}$ Microwave heating technology showed high efficiency in the field of chlorodehydroxylations. ${ }^{[32]}$ Reid et al. combined the microwave heating of ionic liquids and aqueous hydrochloric acid for a range of alcohols with and without added catalysts. ${ }^{[32]}$ Short-chain alcohols have been converted in high yields and selectivity within 10 min under pressurized microwave conditions. The reaction rates were measured to be in the order of 100 times faster than nonmicrowave high-temperature chlorodehydroxylations. Kappe et al. have extended the microwave heating technology with hydrochloric acid to a continuously operating microchip-based flow setup. ${ }^{[33]}$ The full conversion of $n$-butanol was obtained with three equivalents of hydrochloric acid, within 15 min residence time at $160^{\circ} \mathrm{C}$ and 20 bar. If the optimal conditions were applied to $n$-hexanol and $n$-decanol, the reactivity decreased with the increased chain length.

In this study, we convert bulk alcohols into the corresponding chlorides, which are subsequently consumed in the continuous multistep synthesis of antiemetic agents and antihistamines, such as cyclizine, meclizine, a buclizine derivative, and 
cinnarizine. We extend the progress in the field of chlorodehydroxylation by applying milder conditions on a wide scope of substrates in the capillary reactor. This offers a robust and more accessible alternative to microchips, as well as greater versatility with regard to the production volume and rate. As a result of the high abundance of the benzyl moiety in APIs, we started by optimizing the conversion of benzyl alcohol to benzyl chloride. The integration of an inline liquid-liquid separator with the reactor afforded pure benzyl chloride, which was used readily in subsequent reactions. Finally, we demonstrate a step-by-step procedure to perform a four-step continuous synthesis to prepare relevant APIs, such as cinnarizine, cyclizine, and a buclizine derivative.

\section{Results and Discussion}

\section{Synthesis of alkyl chlorides}

The synthesis of chlorides started from similar conditions to those applied by Kappe et al., in which three equivalents of hydrochloric acid was used with $15 \mathrm{~min}$ as a residence time. ${ }^{[33]}$ The results of the initial screening at $120^{\circ} \mathrm{C}$ are shown in Table 1. Already, $88 \%$ of 1 -chlorobutane was obtained in

Table 1. Results of the initial screening of the synthesis of primary chlorides and the optimization of benzyl chloride synthesis. ${ }^{[a]}$

\begin{tabular}{|llllc|} 
Entry & Substrate & $\begin{array}{l}\text { Residence time } \\
{[\mathrm{min}]}\end{array}$ & $\begin{array}{l}\mathrm{HCl} \\
{[\text { equiv.] }}\end{array}$ & $\begin{array}{l}\text { GC yield } \\
{[\%]}\end{array}$ \\
\hline 1 & 1-butanol & 15 & 3 & $\mathbf{8 8}$ \\
2 & 1-butanol & 30 & 3 & $\mathbf{7 7}$ \\
3 & 1-hexanol & 15 & 3 & 46 \\
4 & 1-hexanol & 30 & 3 & $\mathbf{8 2}$ \\
5 & benzyl alcohol & 15 & 3 & $\mathbf{1 0 0}$ \\
6 & benzyl alcohol & 15 & 2 & $97^{\text {[c] }}$ \\
7 & benzyl alcohol & 30 & 2 & $\mathbf{9 8}^{\text {[c] }}$ \\
\hline
\end{tabular}

[a] The experiments were performed at $120^{\circ} \mathrm{C}$ in the microcapillary-based setup (Scheme 1) with aqueous $\mathrm{HCl}$ (36 wt \%). [b] The yields were calculated based on the GC-FID response with respect to 1,3-dimethoxybenzene as an internal standard. Calibrations were performed with corresponding chlorides purchased from Sigma-Aldrich. [c] The presence of unconverted alcohol and dibenzyl ether was detected.

15 min residence time. The extension of the residence time to 30 min increased the formation of dibutyl ether and resulted in a decrease in the yield to $77 \%$. For hexanol, the reaction was slower, and longer residence times improved the yield.

As the benzyl moiety is widely used in API synthesis, our target compound was benzyl chloride. Under the same conditions, $100 \%$ yield of benzyl chloride was obtained without the formation of dibenzyl ether, and no any other byproducts were observed in the GC chromatogram with 15 min residence time. We speculated that the partial solubility of benzyl alcohol in water minimizes the mass transfer limitations. Moreover, as benzyl chloride has a lower solubility in water than benzyl alcohol, the equilibrium of the reaction shifts to the product side. A decrease of the amount of hydrochloric acid with an in- crease of the residence time leads to incomplete conversion along with the formation of dibenzyl ether.

Subsequently, the optimal conditions found for the reaction with benzyl alcohol were applied to other alcohols. The chlorides synthesized at $120^{\circ} \mathrm{C}$ within $15 \mathrm{~min}$ residence time along with their yields are shown in Scheme 1. The chloride derivatives of alcohols are usually volatile because of the presence of weak intermolecular forces, therefore, the products were collected into a sealed vial with deuterated chloroform that contained an external standard (1,3-dimethoxybenzene) and later analyzed as such. In the case of the terminal alkyne 4-pentyn1-ol, the formation of dark viscous agglomerates with a low yield of the chloride was observed. The reaction with tetrahydrofurfuryl alcohol resulted in the partial cleavage of ether and gave a mixture of mono- and disubstituted chloropentanes. If the same conditions were applied to 1,5-pentanediol, full conversion was observed and a $19 \%$ yield of dichloropentane was formed. Aromatic compounds included in the scope differed in their solubility in the aqueous phase, which can explain the differences in yields in the substitution at the benzylic position. For solid compounds such as dodecanol, cyclohexanol, napthalenemethanol, diphenyl methanol, and cinnamyl alcohol, a toluene/acetone (2:1) solvent combination was used to afford solutions of $2.2 \mathrm{M}$.

\section{Utilization of benzyl chloride}

Microflow technology allows the connection of subsequent reactions to afford truly continuous operation with a minimum of manual handling. ${ }^{[34,35]}$ To see the potential in the application of continuous chloride synthesis, we connected the product stream of the benzyl chloride forming reaction to a second reactor in which another nucleophilic substitution would take place. The connection relied on continuous inline liquid-liquid separation, which occurred in a Teflon-membrane-based separator. Similar separators have been used previously in multistep continuous syntheses. ${ }^{[36-38]}$ The design and operation of this separator is described in the Supporting Information. For a complete separation, the correct pressure difference should be applied over the membrane to allow permeate to pass through the membrane without causing a breakthrough of the retained phase, or alternatively, without carrying the permeate within the retentate. The use of a 5 psi $(1 \mathrm{psi}=6.89 \mathrm{kPa})$ backpressure regulator at the aqueous outlet afforded perfect separation with no loss of benzyl chloride. A loop of a larger volume $(35 \mathrm{~mL})$ filled with hydrochloric acid was used in this two-step synthesis to allow a longer uninterrupted operation. After three volumes of the reaction mixture passed through the reactor, separated benzyl chloride was collected in an Erlenmeyer flask $(10 \mathrm{~mL})$. The flow rate of benzyl chloride at the organic outlet of the liquid-liquid separator was $40 \mu \mathrm{L} \mathrm{min}^{-1}$ $\left(21 \mathrm{mmolh}^{-1}\right)$. A collection time of $2 \mathrm{~h}$ was allowed before the product was pumped into a second reactor by using another HPLC pump (Scheme 2).

We chose nitrogen-containing substrates as nucleophiles for the subsequent reaction because of their presence in API structures. Thus piperazine, $n$-methyl piperazine, morpholine, 


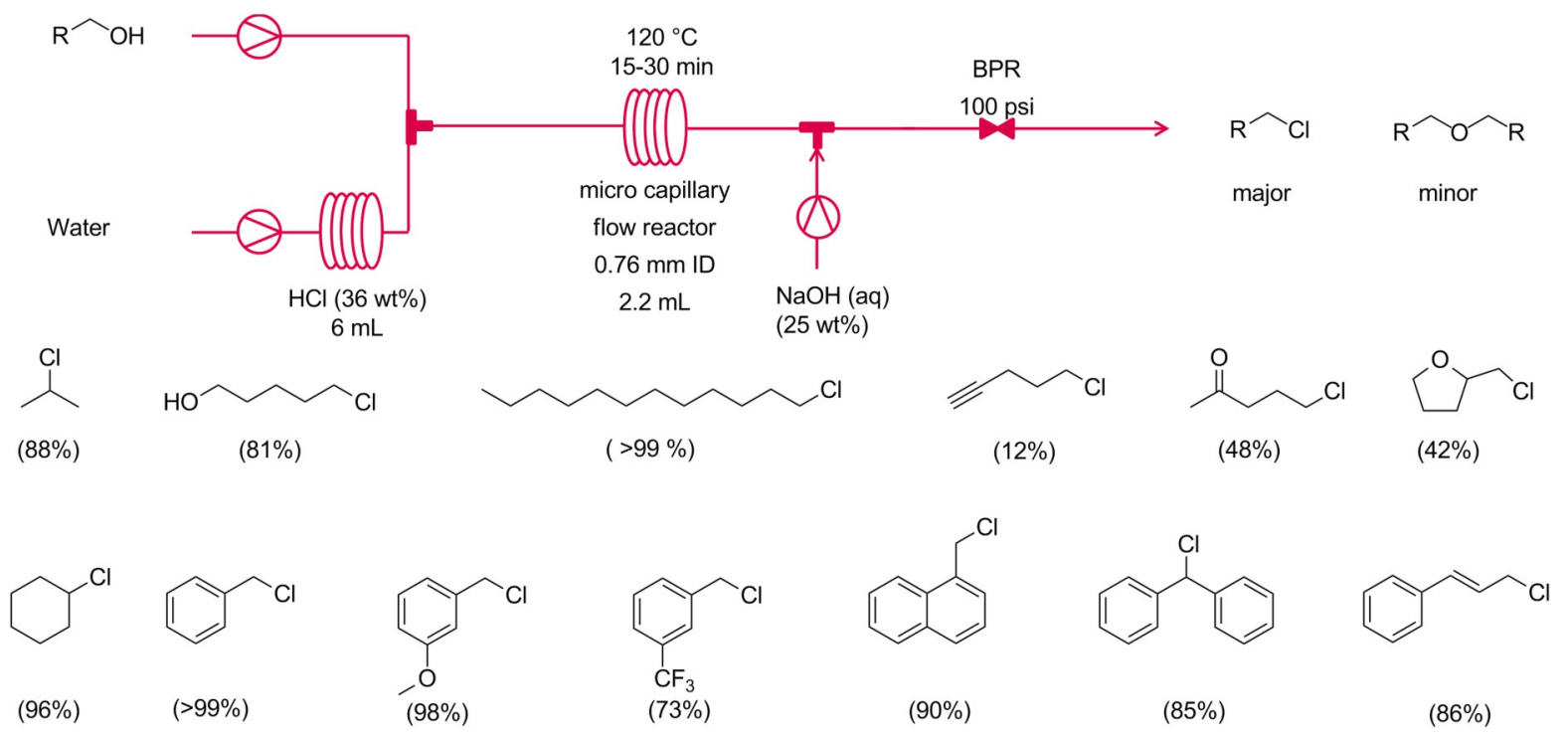

Scheme 1. Top: Schematic representation of the setup used for the current investigation. Bottom: Chlorides synthesized with 3 equivalents of $\mathrm{HCl}$ (aq) at $120^{\circ} \mathrm{C}$ with 15 min residence time. Yields are determined by ${ }^{1} \mathrm{H}$ NMR spectroscopy with respect to 1,3 -dimethoxybenzene as an external standard.

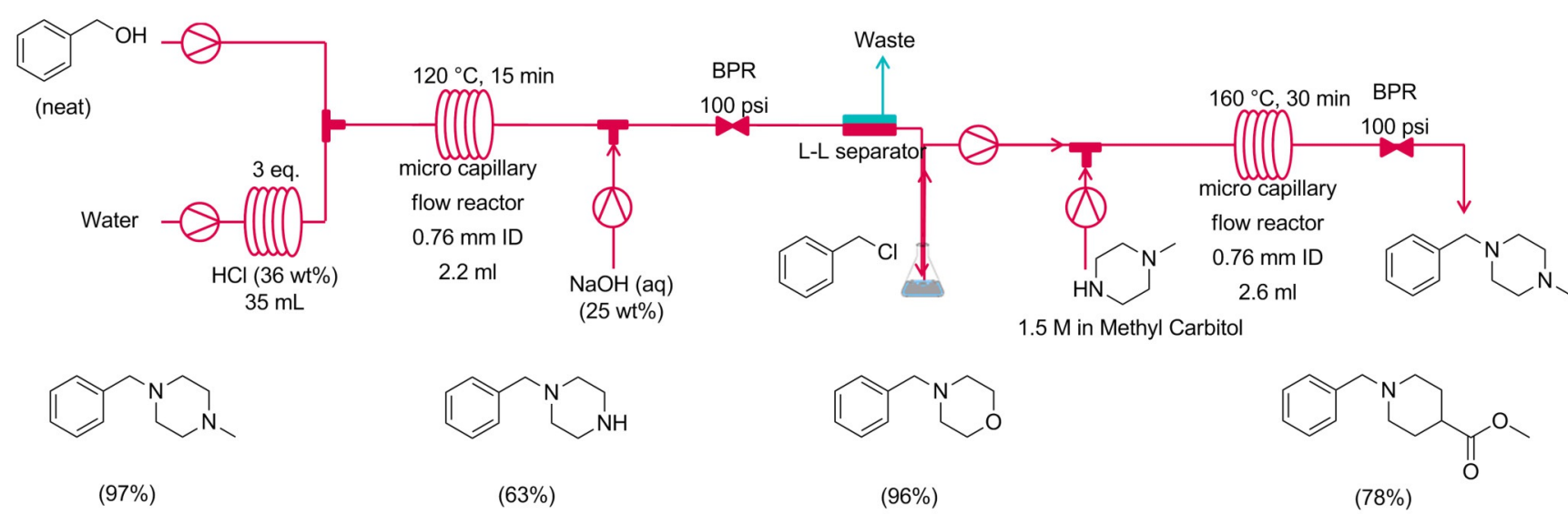

Scheme 2. Schematic representation of the two-step synthesis. The synthesis of benzyl chloride is connected to its separation from the aqueous phase, which takes place in a liquid-liquid-membrane-based separator. The separated neat benzyl chloride is mixed with secondary amines to undergo another nucleophilic substitution. The collected and isolated products are shown along with the corresponding yield values.

and ethyl isonipecotate were used as nucleophiles. In combination with benzyl chloride, piperazine was the only insoluble substrate. The other substrates, even though miscible at first, resulted in precipitate at the end of the reaction. Relatively high volumes of ethanol dissolved the products, which indicated the need for larger amounts of solvent and lower concentrations. Diethylene glycol monomethyl ether (methyl carbitol) afforded homogeneous reaction mixtures with relatively high concentrations of products $(1.1 \mathrm{M})$. For piperazine, the addition of water (methyl carbitol/water 2:1) was needed to keep the product dissolved. The homogeneity of the reactant and product mixtures allowed the translation of batch to continuous conditions. The reaction of benzyl chloride and $n$-methyl piperazine (1.2 equivalents) at $120^{\circ} \mathrm{C}$ with 15 min residence time resulted in an $81 \%$ conversion of benzyl chloride and $100 \%$ selectivity. The conversion increased to $>99 \%$ if the temperature was increased to $160^{\circ} \mathrm{C}$ and residence time to $30 \mathrm{~min}$ with 1.5 equivalents of $n$-methyl piperazine. More details on the optimization are given in the Supporting Information. The isolated yields obtained under these conditions are given in Scheme 2 .

\section{Applications in API synthesis}

The diphenylmethyl moiety is found widely in antiemetic, antimigraine, and antihistamine drugs. The diphenyl piperazine substrate is a key constituent of cyclizine, cinnarizine, meclizine, cetirizine, hydroxyzine, buclizine, dotarizine, and other drugs of the same family. The ease to connect the synthesis of the chloride with a subsequent reaction motivated us to expand the scope to commercially available APIs, such as cyclizine, cinnarizine, and 1-diphenylmethyl-4-benzylpiperazine, 
<smiles>CN1CCN(C(c2ccccc2)c2ccccc2)CC1</smiles><smiles>CC(C)(C)c1ccc(CN2CCN(C(c3ccccc3)c3ccc(Cl)cc3)CC2)cc1</smiles>

Cinnarizine

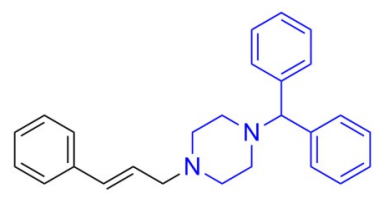

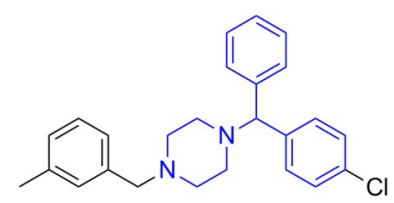

Meclizine
Scheme 3. Generic APIs based on diphenylmethyl piperazine used to treat nausea, vomiting, cerebral apoplexy, and dizziness.

which resemble meclizine and buclizine (Scheme 3). Therefore, the synthesis and inline separation of diphenyl methyl chloride was optimized to pave a way to these final compounds.

\section{Synthesis of cyclizine}

Cyclizine is an antihistamine used in the treatment of nausea, vomiting, and dizziness associated with motion sickness, vertigo, and consequences of anesthesia and the use of opioids. Its chemical name is 1-diphenylmethyl-4-methyl piperazine and it is constructed by the nucleophilic substitution of diphenylmethyl chloride with $n$-methyl piperazine. The two-step setup shown in Scheme 2 was used to connect the formation of chlorodiphenylmethane to the stream of $\mathrm{N}$-methyl piperazine to form cyclizine (Scheme 4). The solubility of diphenyl metha-
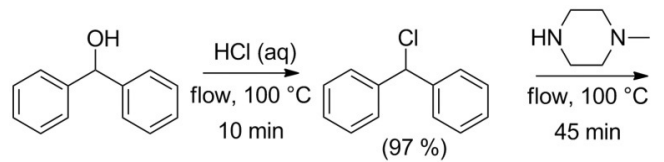

$45 \mathrm{~min}$

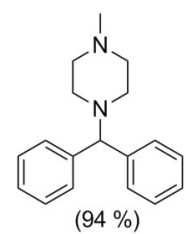

Cyclizine
Scheme 4. Synthesis of cyclizine in continuous flow from diphenylmethanol.

nol was re-evaluated, and acetone proved to be a better solvent, which resulted in a high concentration of $3.1 \mathrm{M}$. High concentrations are desired to minimize the use of solvent. However, upon mixing the stream of diphenylmethanol in acetone with hydrochloric acid, diphenylmethanol precipitated in the T-mixer because of the change in solution composition. The relatively low melting point $\left(69^{\circ} \mathrm{C}\right)$ of diphenylmethanol allowed us to circumvent clogging by immersing the T-mixer in an oil bath. As a result of the high volatility of acetone, a lower temperature of $100^{\circ} \mathrm{C}$ was set as the reaction temperature. As a result of the miscibility of acetone with water, the mass transfer barrier between diphenylmethanol and hydrochloric acid was minimized, which led to a shorter time re- quired for the completion of the reaction. At $100^{\circ} \mathrm{C}$ and $10 \mathrm{~min}$, the full conversion of diphenyl methanol was reached. The evaporation of acetone upon collection resulted in $97 \%$ isolated yield of diphenylmethyl chloride.

To perform a second nucleophilic substitution to synthesize cyclizine, we pumped neat piperazine into the product stream and quenched with $\mathrm{NaOH}$ solution. However, this resulted in clogging, thus we diluted $n$-methyl piperazine with methyl carbitol. As a result, the substantial formation of bisdiphenyl methyl ether was observed because of the presence of water. A maximum selectivity of $80 \%$ towards cyclizine was reached at full conversion from the screening of a wide range of operating conditions. Alternatively, as in the case of benzyl chloride, we connected the product stream of diphenylmethyl chloride to a liquid-liquid separator. The application of 5 psi to the aqueous outlet resulted in the breakthrough of retentate at the permeate outlet. The application of a pressure of 2 psi by using an ultra-low-volume adjustable breakthrough pressure regulator (BPR) on the aqueous outlet with the attachment of tubing $(20 \mathrm{~cm}, 250 \mu \mathrm{m}$ internal diameter) to the organic side outlet gave a perfect qualitative separation. A continuous run on a $7 \mathrm{mmol} \mathrm{h}^{-1}$ scale was performed over $8 \mathrm{~h}$ and resulted in the loss of $0.2 \%$ of organic phase into the aqueous phase. Karl Fischer titration indicated the presence $1.78 \%$ of water in the separated product.

Subsequently, the product was pumped into a T-mixer, in which it was mixed with $n$-methyl piperazine ( 1.5 equivalents) in methyl carbitol to give a final concentration of $1.5 \mathrm{M}$ of diphenylmethyl chloride. At high temperatures, the partial hydrolysis of diphenylmethyl chloride was observed because of the presence of water. Therefore, we decreased the temperature to $100^{\circ} \mathrm{C}$ and increased the residence time to $45 \mathrm{~min}$ to reach full conversion. Transparent crystals precipitated upon cooling. The first crop resulted in $92 \%$ yield of cyclizine with high purity (>99\% GC-MS). The evaporation of acetone and extraction of the rest of the mother liquor afforded $2 \%$ more cyclizine. Impurities detected in the mother liquor were diphenylmethanol and bisdiphenyl methyl ether.

\section{Synthesis of meclizine and buclizine derivatives}

Meclizine and buclizine are alike in terms of their chemical structures and are built from 1-chloro-4-phenylmethyl benzene, piperazine, and benzyl moieties. 1-Chloro-4-phenylmethyl benzene resembles a diphenyl methyl moiety, therefore, we decided to build 1-diphenylmethyl-4-benzylpiperazine as a common derivative. A schematic representation of the overall synthesis is shown in Scheme 5. More details on the assembly of the setup and its operation are provided in the Supporting Information. The synthesis and separation of diphenyl methyl and benzyl chlorides was performed as described above. We started the synthesis of 1-(diphenylmethyl)piperazine with the conditions we used for benzyl chloride (methyl carbitol/water 2:1). However, at the full conversion of chlorodiphenylmethane, only a minor formation of 1-(diphenylmethyl)piperazine $(<15 \%$ yield) was formed, and the major products were $\{[2-(2-$ methoxyethoxy)ethoxy] methylene $\}$ dibenzene and 


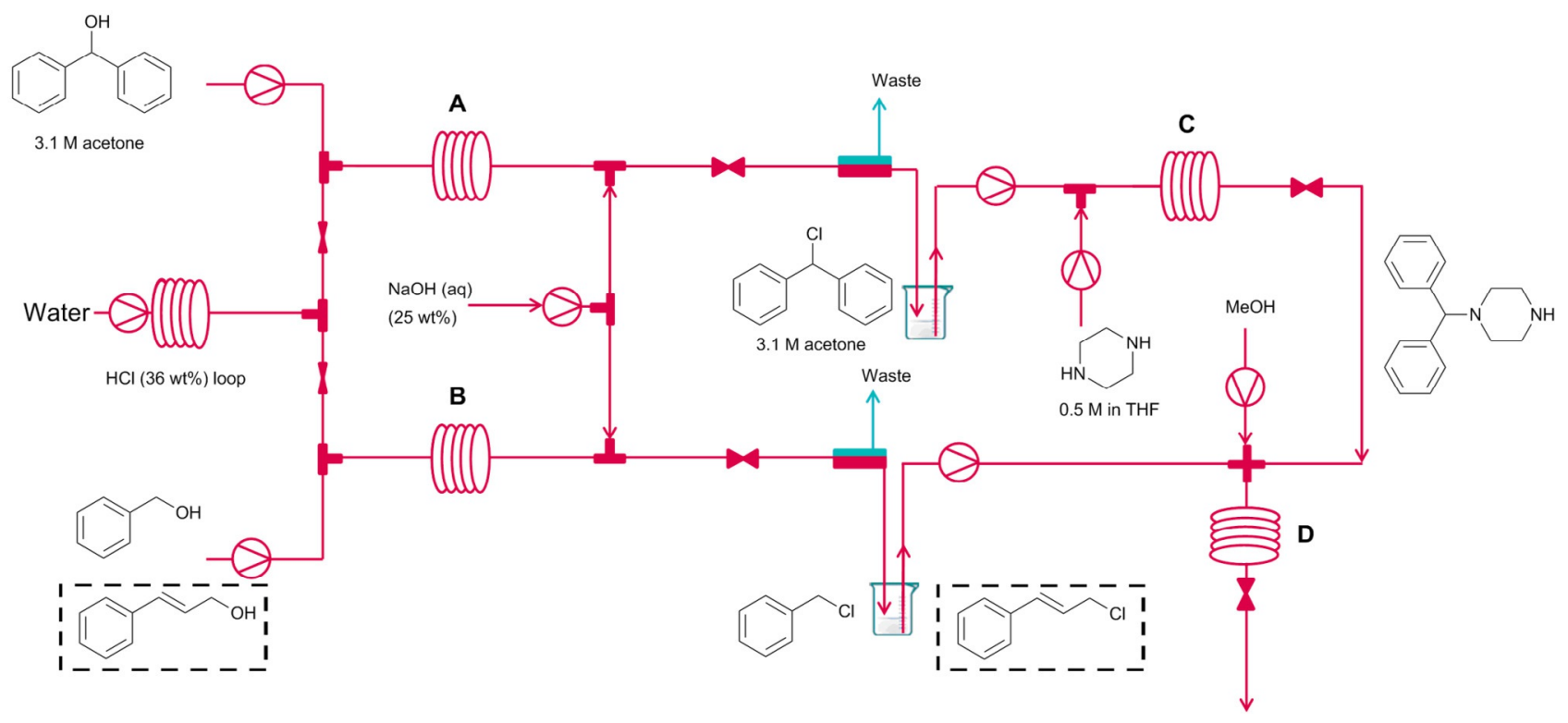

\begin{tabular}{|c|c|c|}
\hline Reactor/Parameters & $T\left[{ }^{\circ} \mathrm{C}\right]$ & \\
\hline A & 100 & \\
\hline B & $120 \quad 60^{[a]}:$ & \\
\hline C & 150 & \\
\hline D & $150: 100$ [ā]: & \\
\hline
\end{tabular}

\begin{tabular}{|c|c|}
\hline$t$ [min] & Yield [\%] \\
\hline 10 & 97 \\
\hline 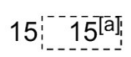 & $99: 95 \bar{I}^{\mathrm{I} T}$ \\
\hline 45 & 95 \\
\hline 15 & $87^{[\mathrm{b}]}: 82^{[a, b]}$ \\
\hline
\end{tabular}

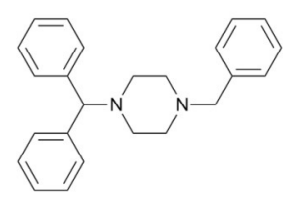

Buclizine derivative

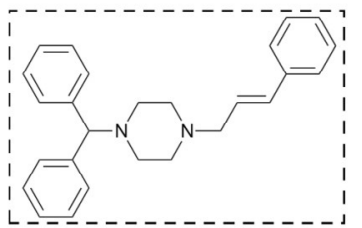

Cinnarizine

[a] Reaction conditions for synthesis of cinnarizine. [b] Isolated yield.

Scheme 5. Schematic representation of the four-step synthesis with tabulated conditions. The synthesis and separation of chlorides are connected to the subsequent reactions. The two steps of the buclizine derivative and cinnarizine were the same. To differentiate the rest of the sequence cinnarizine reagents are highlighted in dashed rectangles.

diphenylmethanol. Similar results were obtained if ethanol and methanol were used as solvents. We concluded that because of the higher steric hindrance of diphenylmethyl chloride than that of benzyl chloride, nucleophilic substitution by smaller molecules, such as water or alkoxides, was faster. Alternative organic solvents such as toluene, heptane, DMF, acetonitrile, dimethoxyethane, methyltetrahydrofuran, 4-methylpentanone, acetone, dichloromethane, and various combinations could not dissolve piperazine. A combination of dichloromethane and acetone (4:1) dissolved piperazine with a maximum concentration of $1.26 \mathrm{M}$. However, the mixture was metastable and led to the precipitation of piperazine if it was pumped through the reactor tubing. Therefore, we switched to THF, which dissolved piperazine with concentrations only up to $0.5 \mathrm{M}$. Nevertheless, precipitation within the reactor was still observed. We switched to a tubular reactor with a larger internal diameter of $1.58 \mathrm{~mm}$ to allow the visual observation of the precipitate formation. We stopped the reaction and pushed out the precipitate to see that it was unreacted piperazine. One of the causes for the precipitation could be bubble formation within the reactor followed by a decrease of available solvent because of evaporation, which would cause the precipitation of piperazine. Thus, we increased the pressure from the $100 \mathrm{psi}$ re- quired theoretically to $250 \mathrm{psi}$. As a result less precipitation was observed. The fact that the crystals formed towards the end of the reactor led us to believe that it might be piperazine hydrochloride or 1-(diphenylmethyl)piperazine hydrochloride. We mixed water into the product stream to dissolve the unreacted reactant to allow the optimization of the reaction. If the conversion was incomplete, diphenyl methanol was formed upon mixing with water at the outlet. As a result of a lower concentration and the use of a nonpolar solvent, the reaction was slower. Full conversion with $92 \%$ selectivity towards 1-(diphenylmethyl)piperazine was observed at $150^{\circ} \mathrm{C}$ with 45 min of residence time and 1.5 equivalents of piperazine. Finally, no precipitation was observed if water addition stopped after two volumes of the reactants had passed.

Subsequently, to synthesize buclizine and the meclizine derivative, 1-(diphenylmethyl)piperazine needed to react with the synthesized and separated benzyl chloride. Before the flow experiments, batch investigations showed the precipitation of the product from the reaction mixture. Methanol, used in an equivolumetric amount with respect to the product mixture, was sufficient to afford homogeneity. Thus, methanol along with 2.0 equivalents of benzyl chloride were injected into a product stream of 1-(diphenylmethyl)piperazine through 
a cross (Scheme 5). At $100^{\circ} \mathrm{C}$ and 15 min residence time, $67 \%$ yield was observed. This yield could be further increased to $71 \%$ if the temperature was increased to $120^{\circ} \mathrm{C}$. An increase of the temperature to $150^{\circ} \mathrm{C}$ resulted in the full conversion of 1 (diphenylmethyl)piperazine, and a yield of $89 \%$ based on diphenyl methanol was obtained. Benzyl piperazine, dibenzylpiperazine, benzyl alcohol, and benzyl methyl ether were formed as byproducts in the final product mixture. Isolated yield experiments were performed without the addition of the internal standard. To separate the product, all volatile solvents were removed from the collected sample. Water was added to the product, and the $\mathrm{pH}$ was adjusted to $<3$. Ethyl acetate was then used to extract the excess of benzyl chloride and formed benzyl methyl ether. Subsequently, the $\mathrm{pH}$ of the aqueous phase was adjusted to 4 with acetic acid/sodium acetate trihydrate buffer. At this point, secondary amines were extracted into the aqueous phase. The evaporation of ethyl acetate followed by the recrystallization of 1-diphenylmethyl-4-benzylpiperazine from EtOH afforded $87 \%$ isolated yield.

\section{Synthesis of cinnarizine}

To synthesize cinnarizine, 1-diphenylmethyl piperazine needed to react with the synthesized and separated cinnamyl chloride. The optimal conditions for benzyl chloride synthesis were not optimal for the synthesis of cinnamyl chloride. Lower temperatures, $60^{\circ} \mathrm{C}$, gave a higher selectivity and a maximum yield of $95 \%$ yield at $5.0 \mathrm{M}$ concentration in toluene. Batch investigations showed that homogeneous conditions were afforded if the final reaction was performed in a solution of equal volumes of acetone and $25 \mathrm{wt} \% \mathrm{NaOH}$ in water. Therefore, the solution and 2.0 equivalents of cinnamyl chloride were injected into a product stream of 1-(diphenylmethyl)piperazine through a cross without its intermediate separation. At $100^{\circ} \mathrm{C}$ and with 15 min residence time, a $77 \%$ yield was observed, and an increase of the time to $30 \mathrm{~min}$ led to the full conversion of 1-(diphenylmethyl)piperazine and an $85 \%$ yield of cinnarizine based on diphenyl methanol. Isolated yield experiments were performed without the addition of an internal standard in a similar manner to the synthesis of 1-diphenylmethyl-4-benzylpiperazine. $\mathrm{MeOH}$ was used for the recrystallization of cinnarizine to afford an $82 \%$ isolated yield.

\section{Conclusions}

We have demonstrated a simplification and acceleration of chemical reactions with the help of microflow technology. Bulk alcohols were used in a sequence of nucleophilic substitution reactions to build meclizine, a buclizine derivative, and commercially available cyclizine and cinnarizine. Our continuousflow protocol delivered an excellent yield of benzyl chloride in 15 min residence time under superheated conditions of $120^{\circ} \mathrm{C}$ and 100 psi using hydrochloric acid as the chlorinating agent. The same conditions were applied to a wide variety of aliphatic and aromatic alcohols.

To connect chlorodehydroxylation reactions to a subsequent reaction step, a membrane-based liquid-liquid separator was designed and integrated in the reactor network. This allowed the separation of intermediate chlorides and their consumption in the construction of the target molecules. Overall four steps were realized in $90 \mathrm{~min}$ with good yields at a production rate of $2 \mathrm{mmolh}^{-1}$ of final products.

As a result of its corrosive nature, hydrochloric acid has to be isolated from the pumps and was delivered through a loop, which has to be refilled while the continuous operation of chlorination steps is paused. Therefore, the greatest limitation of this method is the supply of hydrochloric acid. A $\mathrm{HCl}$ gas supply could revolutionize the synthesis, however, its supply into a microflow environment has not yet been developed. The methodology demonstrated herein allows an easy and accessible route to chlorides.

\section{Experimental Section}

Operating platform: The working setup used in the current investigation was built from acid-resistant HPLC pumps, fluorinated ethylene propylene (FEP) tubing, and inline BPRs. The use of the HPLC pump for hydrochloric acid resulted in a malfunction of the pump. After a short operation time, the pump would stop delivering the acid to the reactor. Upon purging the pump, gas slugs were observed, which led to the conclusion that the pump malfunctioned because of the accumulation of hydrogen chloride gas within the pump head. Thus, $\mathrm{HCl}$ loops of $6 \mathrm{~mL}$ and later of $35 \mathrm{~mL}$ (Scheme 1, top) filled with concentrated hydrochloric acid (36 wt \%) were used as the $\mathrm{HCl}$ source. Alcohols were pumped in their neat form and mixed with $\mathrm{HCl}$ within a polytetrafluoroethylene (PTFE) T-mixer. A reactor with an inner diameter of $762 \mu \mathrm{m}$ and volume of $2.2 \mathrm{~mL}$ was used. The volume could be increased by using more tubing, however, to minimize the use of chemicals, we kept it average. Finally, because we started investigations at $120^{\circ} \mathrm{C}$ (superheated conditions), a BPR was added to avoid boiling within the reactor. A stream of $\mathrm{NaOH}$ ( $25 \mathrm{wt} \%$ ) was introduced before the BPR to avoid its corrosion. More information regarding the setup is provided in the Supporting Information.

Synthesis of alkyl chlorides: All of the pumps were purged with isopropanol. BPRs with cartridges of 1000 psi were attached immediately after the pressure sensors of the HPLC pumps to ensure a constant flow at lower flow rates. Neat alcohol substrates were used as received from a supplier. Pumps were purged with substrate, water, and $25 \mathrm{wt} \% \mathrm{NaOH}$, respectively. The $\mathrm{HCl}$ loop was filled with $\mathrm{HCl}$ from a syringe with a luer adapter. With the syringe still attached to one end, another was connected to the T-mixer, and the first end was connected to a union. Water was pumped into the loop to deliver $\mathrm{HCl}$ to the reactor through a T-mixer. Subsequently, the pumps were set to the required flow rates and the entire setup (tubing) was filled with the fluid. The BPR was attached, and the capillary reactor was immersed into a heating bath (IKA) at the operating temperature. The residence time was varied by adjusting the flow rates while the reactor volume was kept the same $(2.2 \mathrm{~mL})$. Flow rates were recalculated for each substrate based on their molecular weight and density. For benzyl alcohol with 15 min residence time, benzyl alcohol, $\mathrm{HCl}$, and $\mathrm{NaOH}$ solution were pumped at 40,110 , and $410 \mu \mathrm{L} \mathrm{min}^{-1}$, respectively. The $\mathrm{HCl}$ loop was refilled after $80 \%$ of the initial volume has been used. Before the refill, the capillary reactor was cooled to RT, and the nut of the union was unscrewed to refill the loop. 
NOTE: Dodecanol, cyclohexanol, napthalenemethanol, diphenyl methanol, and cinnamyl alcohol are solids under atmospheric conditions and, therefore, needed addition of toluene/acetone (2:1) to be able to be delivered into a flow setup. The maximum common concentration was $2.2 \mathrm{M}$.

Utilization of benzyl chloride and two-step synthesis: All five pumps were purged with isopropanol. The $35 \mathrm{~mL} \mathrm{HCl}$ loop was filled with $\mathrm{HCl}$ from a syringe with a luer adapter. Water was pumped into the loop to deliver the $\mathrm{HCl}$. Thymol Blue was added to $25 \mathrm{wt} \% \mathrm{NaOH}$ solution to assess the separation efficiency at the liquid-liquid separator visually. The outlet of the reactor BPR was connected directly to the liquid-liquid separator.

The separator was based on two ethylene tetrafluoroethylene inserts. Both inserts had an identical channel in the shape of an ellipse with $1 \mathrm{~mm}$ depth. The upper insert had two ports, one for the inlet of a mixture and another for the outlet of aqueous phase. The lower insert had only one port for the outlet of the organic phase. Extra space was created next to the operating channel to detect leakage caused by the overpressure of the unit. The upper limit of the unit was 250 psi. A Zefluor membrane, available from Pall Corporation, was squeezed between the inserts. Two stainlesssteel holders were used to create a shell for the separator. A picture and a technical drawing of the device are given in the Supporting Information. Pressure over the membrane was applied by connecting BPRs to the outlets of the separator. A BPR with 5 psi cartridge was connected to the aqueous outlet and resulted in a perfect separation with no loss of benzyl chloride, confirmed by collected volumes of the permeate and retentate.

After three volumes of the reaction mixture had passed through the reactor, the separated benzyl chloride was collected in an Erlenmeyer flask $(10 \mathrm{~mL})$. A feed tube for the other pump was immersed into the flask in which the benzyl chloride was collected. The pump delivered separated benzyl chloride to a T-mixer in which it was mixed with methyl piperazine in methyl carbitol $(1.5 \mathrm{M})$. Optimization consisted of screening the effects of temperature, residence time, and the amount and concentration of methyl piperazine. 1,3,5-Trimethoxybenzene was used as internal standard and was added to the methyl piperazine solution. The yield was calculated based on the internal standard from a GC with flame ionization detection (FID) response. A temperature of $160^{\circ} \mathrm{C}$, $30 \mathrm{~min}$, and 1.5 equivalents of methyl piperazine were optimum and resulted in an isolated yield of $97 \%$.

Synthesis of 1-diphenylmethyl-4-benzylpiperazine: All eight pumps were purged with isopropanol. Reactors with a smaller volume were prepared for synthesis of chlorides because of the insufficient number of pumps and the need to use the $\mathrm{HCl}$ loop for both chlorinations. Diphenyl methanol was dissolved in acetone at $3.1 \mathrm{M}$ concentration. Four pumps were purged with diphenyl methanol solution, water, benzyl alcohol, and $25 \mathrm{wt} \% \mathrm{NaOH}$. Subsequently, the pumps were set to the required flow rates. The diphenyl methanol pump was set to $0.035 \mathrm{~mL} \mathrm{~min}^{-1}$ to allow a $10 \mathrm{~min}$ residence time in the $1.0 \mathrm{~mL}$ reactor and $15 \mathrm{~min}$ in the $1.5 \mathrm{~mL}$ reactor. The water pump was set to $0.138 \mathrm{~mL} \mathrm{~min}^{-1}$ to deliver $\mathrm{HCl}$ to both of the reactors. In this way, benzyl alcohol pumped by third pump at $0.025 \mathrm{~mL} \mathrm{~min}^{-1}$ received $7 \%$ less of the $\mathrm{HCl}$ required theoretically, that is, 2.9 equivalents with respect to benzyl alcohol. However, this was sufficient for a full conversion, and no loss of performance was observed. Reactor outlets were connected to T-mixer to be mixed with $\mathrm{NaOH}$ ( $25 \mathrm{wt} \%$ ) pumped by the fourth pump at $0.4 \mathrm{~mL} \mathrm{~min}{ }^{-1}$. The third ends of the T-mixers were connected to BPRs of $100 \mathrm{psi}$, which were connected to two liquid-liquid separators. The adjustable BPR (M-410) was connected to the aqueous outlet of the diphenylmethyl chloride separator to apply 2 psi, and the product was collected on the organic outlet through a tubing of $20 \mathrm{~cm}$ with $250 \mu \mathrm{m}$ ID. Meanwhile, the BPR with a 5 psi cartridge was connected to the aqueous outlet of the benzyl chloride separator. Both reactors were then immersed in heating baths, and after 30 min of operation diphenylmethyl chloride was collected, whereas benzyl chloride was collected after $45 \mathrm{~min}$. After $2 \mathrm{~h}$ of operation, the inlet tubing for the fifth pump was immersed in the collection flask of diphenylmethyl chloride, and the flow rate was set to $1 \mathrm{~mL} \mathrm{~min}{ }^{-1}$ for $3 \mathrm{~min}$ to fill the inlet tubing (1.5 m, 1/16" ID, 1/8" OD). Pump 6 was purged with $0.5 \mathrm{M}$ of piperazine solution. Next, the flow rate of the fifth pump was set

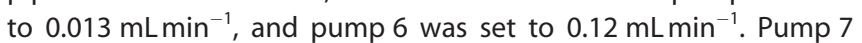
was set to $0.15 \mathrm{~mL} \mathrm{~min}^{-1}$ to pump $\mathrm{MeOH}$ into the cross, and the inlet tubing of pump 8 was filled with collected benzyl chloride and set to $0.01 \mathrm{~mL} \mathrm{~min}^{-1}$. The reactor tubing for both reactors (6 and $4.4 \mathrm{~mL}$ ) was filled with THF with a syringe, and the reactors were connected to a cross. A second reactor of $4.4 \mathrm{~mL}$ was connected to the 250 psi BPR at another end. Both reactors were then immersed into one heating bath. The product was collected after $150 \mathrm{~min}$ from the start of the heating of the reactors. The collected product was separated from all volatile solvents by using a rotary evaporator. Water ( 5 volumes) and ethyl acetate ( 5 volumes) were added to the collected sample and the $\mathrm{pH}$ was decreased to 3 by the addition of $\mathrm{HCl}$. Ethyl acetate was then used to extract the excess of benzyl chloride and formed benzyl methyl ether. Subsequently, the $\mathrm{pH}$ of the aqueous phase was adjusted to 4 with acetic acid/sodium acetate trihydrate buffer. At this point, the secondary amines were extracted into an aqueous phase. The evaporation of ethyl acetate followed by the recrystallization of 1-diphenylmethyl-4-benzylpiperazine from EtOH afforded an $87 \%$ isolated yield.

\section{Acknowledgements}

We would like to thank Nico Erdmann, Mark Graus, Slavisa Jovic, Erik van Herk, and Bert Metten for their help during different stages of our investigation. Funding from the Advanced European Research Council Grant "Novel Process Windows-Boosted Micro Process Technology" (Grant number: 267443) is gratefully acknowledged.

Keywords: alcohols - halogenation - hydrogen chloride multicomponent reactions $\cdot$ synthesis design

[1] J. S. Carey, D. Laffan in Pharmaceutical Process Development: Current Chemical and Engineering Challenges, The Royal Society of Chemistry, London, 2011, pp. 39-65.

[2] J. S. Carey, D. Laffan, C. Thomson, M. T. Williams, Org. Biomol. Chem. 2006, 4, 2337-2347.

[3] R. C. Larock, Comprehensive Organic Transformations, 2nd ed., WileyVCH, Weinheim, 1999, p. 689.

[4] R. G. Weiss, E. I. Snyder, J. Chem. Soc. Chem. Commun. 1968, 1358 1359.

[5] A. Dubey, A. K. Upadhyay, P. Kumar, Tetrahedron Lett. 2010, 51, $744-$ 746.

[6] Y. Kimura, D. Matsuura, Int. J. Org. Chem. 2013, 3, 1-7.

[7] R. Ding, Y. He, X. Wang, J. Xu, Y. Chen, M. Feng, C. Qi, Molecules 2011, $16,5665-5673$

[8] L. De Luca, G. Giacomelli, A. Porcheddu, Org. Lett. 2002, 4, 553-555.

[9] R. M. Denton, J. An, B. Adeniran, Chem. Commun. 2010, 46, 3025-3027. 
[10] C. E. Ayala, A. Villalpando, A. L. Nguyen, G. T. McCandless, R. Kartika, Org. Lett. 2012, 14, 3676-3679.

[11] R. K. Henderson, C. Jiménez-González, D. J. C. Constable, S. R. Alston, G. G. A. Inglis, G. Fisher, J. Sherwood, S. P. Binks, A. D. Curzons, Green Chem. 2011, 13, 854 .

[12] J. P. Adams, C. M. Alder, I. Andrews, A. M. Bullion, M. Campbell-Crawford, M. G. Darcy, J. D. Hayler, R. K. Henderson, C. A. Oare, I. Pendrak, A. M Redman, L. E. Shuster, H. F. Sneddon, M. D. Walker, Green Chem. 2013 $15,1542-1549$.

[13] W. Gerrard, E. MacKlen, J. Appl. Chem. 1956, 6, 241 - 244.

[14] L. Vaccaro, D. Lanari, A. Marrocchi, G. Strappaveccia, Green Chem. 2014, $16,3680$.

[15] B. Gutmann, D. Cantillo, C. O. Kappe, Angew. Chem. Int. Ed. 2015, 54, 6688-6728; Angew. Chem. 2015, 127, 6788-6832.

[16] S. G. Newman, K. F. Jensen, Green Chem. 2013, 15, 1456.

[17] V. Hessel, D. Kralisch, N. Kockmann, Novel Process Windows: Innovative Gates to Intensified and Sustainable Chemical Processes, Wiley-VCH, Weinheim, 2015.

[18] T. Razzaq, C. O. Kappe, Chem. Asian J. 2010, 5, 1274-1289.

[19] S. Borukhova, A. D. Seeger, T. Noël, Q. Wang, M. Busch, V. Hessel, ChemSusChem 2015, 8, 504-512.

[20] E. R. Murphy, J. R. Martinelli, N. Zaborenko, S. L. Buchwald, K. F. Jensen, Angew. Chem. 2007, 119, 1764-1767.

[21] S. Marre, A. Adamo, S. Basak, C. Aymonier, K. F. Jensen, Ind. Eng. Chem. Res. 2010, 49, 11310-11320.

[22] I. R. Baxendale, J. Deeley, C. M. Griffiths-Jones, S. V. Ley, S. Saaby, G. K. Tranmer, Chem. Commun. 2006, 2566-2568.

[23] J. C. Pastre, D. L. Browne, S. V. Ley, Chem. Soc. Rev. 2013, 42, 8849-8869.

[24] P. Zhang, M. G. Russell, T. F. Jamison, Org. Process Res. Dev. 2014, 18, $1567-1570$.
[25] S. Mascia, P. L. Heider, H. Zhang, R. Lakerveld, B. Benyahia, P. I. Barton R. D. Braatz, C. L. Cooney, J. M. B. Evans, T. F. Jamison, K. F. Jensen, A. S. Myerson, B. L. Trout, Angew. Chem. Int. Ed. 2013, 52, 12359-12363; Angew. Chem. 2013, 125, 12585-12589.

[26] D. Webb, T. F. Jamison, Chem. Sci. 2010, 1, 675.

[27] R. L. Hartman, K. F. Jensen, Lab Chip 2009, 9, 2495-2507.

[28] R. L. Hartman, H. R. Sahoo, B. C. Yen, K. F. Jensen, Lab Chip 2009, 9, $1843-1849$.

[29] D. R. Snead, T. F. Jamison, Chem. Sci. 2013, 4, 2822-2827.

[30] P. Tundo, G. Moraglio, F. Trotta, Ind. Eng. Chem. Res. 1989, 28, $881-890$

[31] P. Tundo, M. Selva, Green Chem. 2005, 7, 464.

[32] M. C. Reid, J. H. Clark, D. J. Macquarrie, Green Chem. 2006, 8, 437.

[33] B. Reichart, G. Tekautz, C. O. Kappe, Org. Process Res. Dev. 2013, 17, $152-157$.

[34] S. Borukhova, V. Hessel in Process Intensification for Green Chemistry (Eds.: K. Boodhoo, A. Harvey), Wiley, Weinheim, 2013, pp. 91-156.

[35] V. Hessel, D. Kralisch, N. Kockmann, T. Noël, Q. Wang, ChemSusChem 2013, 6, 746-789.

[36] A. Adamo, P. L. Heider, N. Weeranoppanant, K. F. Jensen, Ind. Eng. Chem. Res. 2013, 52, $10802-10808$.

[37] A. E. Cervera-Padrell, S. T. Morthensen, D. J. Lewandowski, T. Skovby, S. Kiil, K. V. Gernaey, Org. Process Res. Dev. 2012, 16, 888-900.

[38] D. R. Snead, T. F. Jamison, Angew. Chem. Int. Ed. 2015, 54, 983-987; Angew. Chem. 2015, 127, 997-1001.

Received: October 9, 2015

Published online on December 9, 2015 